\title{
Relationship between bacilloscopy and operational classification of Hansen's disease in patients with reactions*
}

\author{
Marcel Alex Soares dos Santos ${ }^{1}$ \\ Elisangela Samartin Pegas ${ }^{3}$
}

\author{
Larissa Mondadori Mercadante ${ }^{2}$ \\ Bogdana Victoria Kadunc ${ }^{2}$
}

DOI: http:/ / dx.doi.org/10.1590/abd1806-4841.20186725

\begin{abstract}
Leprosy can be classified according to its operational form as paucibacillary or multibacillary. Bacilloscopy integrates its diagnostic armamentarium. Patients with the disease may present leprosy reactions. This study describes the association of bacilloscopy results and the type of operational classification of leprosy in patients with leprosy reactions. Medical records were analyzed at a reference center between 2010 and 2015. Reactions occurred in almost half of the patients, making their identification important. The bacilloscopic and operational characterization indicates a greater occurrence of leprosy reactions in patients with positive bacilloscopy and also in multibacillary.
\end{abstract}

Keywords: Classification; Diagnosis; Leprosy

Hansen's disease is an infectious and contagious, granulomatous and chronic disease caused by the Gram-positive, acid-fast bacillus Mycobacterium leprae. Patients can be classified according to the operational form of the disease, being those with up to 5 lesions considered paucibacillary, and those with more than 5 lesions, multibacillary. ${ }^{1-3}$ Bacilloscopy is a test that is part of the diagnostic armamentarium for Hansen's disease. It is the microscopic analysis of lymph smear with Ziehl-Neelsen stain, in order to identify the bacilli. Patients with positive bacilloscopy are considered multibacillary, regardless of the number of lesions. ${ }^{4}$ Hansen's disease patients can develop reactions, acute phenomena of immunologic and inflammatory changes in face of $M$. leprae antigens. Type 1 reactions are due to late hypersensitivity with the activation of TH1 and TH17 pathways and occur in borderline patients. In general, they reflect an improvement of the defenses against $M$. leprae. Type 2 reactions are caused by the compensatory exacerbation of the humoral immunity via activation of the TH2 and TH17 pathways in the lepromatous pole of the disease..$^{1-5}$ Reactions represent not very well known im- munologic responses and reflect a peculiar clinical picture, therefore requiring the dermatologist's attention. ${ }^{4}$ The objective of this study is to describe the relationship between bacilloscopy and the operational classification of Hansen's disease in patients with reactions. It is an observational, cross-sectional study, where information in the files of patients with notified Hansen's disease from a reference center in the municipality of Campinas (SP) from 2010 to 2015, with type 1 or type 2 reactions $(n=41)$ was analyzed. The variables analyzed were: bacilloscopy at diagnosis, operational classification and type of reaction. Statistical analysis was performed using simple frequencies. Ninety-one cases of Hansen's disease were diagnosed and notified in the period studied. Of those, 41 cases $(45 \%)$ had some type of reaction. Twenty-five (61\%) patients had type 1 reaction, 11 (27\%) patients had type 2 reactions and $5(12 \%)$ patients had both types of reaction in different times of the course of the disease (Table 1). Among those with type 1 reaction, 18 (72\%) cases had negative bacilloscopy at diagnosis (Graph 1A). Twenty-one (84\%) cases had an operational classification of multibacillary and $4(16 \%)$ cases, of paucibacillary

\footnotetext{
Received 21 November 2016.

Accepted 29 August 2017.

* Work conducted at Pontifícia Universidade Católica de Campinas (PUC-Campinas), Campinas (SP), Brazil.

Financial support: None.

Conflict of interest: None.

Post-graduation Program in Health Sciences, Pontifícia Universidade Católica de Campinas (PUC-Campinas), Campinas (SP), Brazil.

Service of Dermatology, Pontifícia Universidade Católica de Campinas (PUC-Campinas), Campinas (SP), Brazil.

Outpatient clinic of Hansen's disease, Pontifícia Universidade Católica de Campinas (PUC-Campinas), Campinas (SP), Brazil.
}

MAILING ADDRESS:

Larissa Mondadori Mercadante

E-mail: larissa_40@yahoo.com.br

(C2018 by Anais Brasileiros de Dermatologia 
TABLE 1: Distribution of those with reactions according the bacilloscopy features and operational classification of Hansen's disease

\begin{tabular}{lllllllll} 
& \multicolumn{3}{c}{ Bacilloscopy } & \multicolumn{3}{c}{ Operational classification } \\
\cline { 2 - 9 } & \multicolumn{2}{c}{ Positive } & \multicolumn{2}{c}{ Negative } & \multicolumn{2}{c}{ Paucibacillary } & \multicolumn{2}{c}{ Multibacillary } \\
\cline { 2 - 9 } & $\mathbf{n}$ & $\%$ & $\mathbf{n}$ & $\%$ & $\mathbf{n}$ & $\%$ & $\mathbf{n}$ & $\%$ \\
\hline Type 1 reaction $(\mathrm{n}=25)$ & 7 & 28 & 18 & 72 & 4 & 16 & 21 & 84 \\
Type 2 reaction $(\mathrm{n}=11)$ & 11 & 100 & 0 & 0 & 0 & 0 & 11 & 100 \\
Both $(\mathrm{n}=5)$ & 5 & 100 & 0 & 0 & 0 & 0 & 5 & 100
\end{tabular}

\section{A. Distribution of the bacilloscopy results in those with reaction}

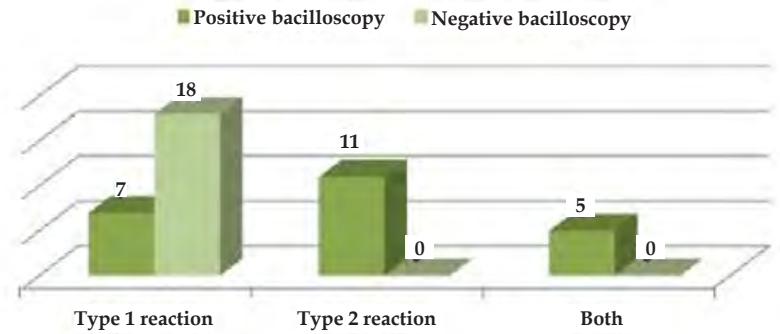

B. Distribution of the operational classification in those with reactions

aucibacillary operational classification $=$ Multibacillary operational classification

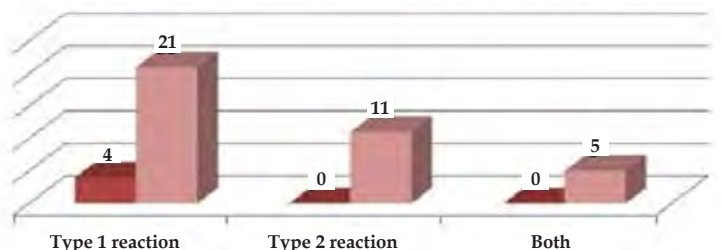

Graph 1: A. Bacilloscopy of those with reactions. B. Operational classification of those with reactions

(Graph 1B). Among those with type 2 reaction, all cases (100\%) had positive bacilloscopy at the time of diagnosis and an operational classification of multibacillary. Of the patients who developed type 1 and type 2 reaction sometime during the course of Hansen's disease, $100 \%$ (five cases) had positive bacilloscopy and were multibacillary. Firstly, we observed that the percentage of patients with positive bacilloscopy who developed a reaction $(56 \%)$ was higher than the percentage of patients with negative bacilloscopy who developed a reaction $(44 \%)$. Higher frequencies of type 1 reaction were identified among patients with negative bacilloscopy and type 2 reaction among individuals with positive bacilloscopy. However, most patients in both reaction groups had an operational classification of multibacillary. The predominance of negative bacilloscopy among those with type 1 reaction is against most published studies, for it is known that there is a positive relationship between the amount of bacilli and the appearance of a reaction and that the presence of high bacteriological indexes is a risk factor for the development of either reaction. ${ }^{2}$ This finding can be explained by the higher occurrence of a type 1 reaction among those with borderline Hansen's disease, in whom there is a more effective cellular immune response and a lower bacillary load than in the lepromatous pole. Another possibility would be the occurrence of a type 1 reaction associated to a negative bacilloscopy in borderline tuberculoid patients, who are closer to the tuberculoid pole on the immunology and histopathology. ${ }^{1-3}$ Other possible causes for the result could be the insufficient collection of lymph or unavailability of the Faraco-Fite stain at the laboratory of the university service where the study was performed (this stain is more sensitive to identify the bacillus on histology from skin samples), thus interfering with the operational classification of the patients. ${ }^{6,7}$ The other findings are similar to other published studies. ${ }^{8,9} \mathrm{In}$ the period studied, there was a higher prevalence of type 1 reaction, but this is not a reassuring finding: although being systemically less severe, this type of reaction generates more signs of physical disability, many times accompanied by neuritis, which is responsible for important injury and sequelae, affecting the patients' quality of life. ${ }^{2,8}$ This picture is more frequent in those with type 1 reaction than those with type 2 reaction, even when both groups are multibacillary. 2,8 For this reason, it is not accurate to think that patients with type 1 reactions and operational classification of multibacillary, but with negative bacilloscopy, have a better prognosis because they have a lower bacillary load. ${ }^{8,9}$ Considering that almost half the patients had a reaction, we can conclude that it is extremely important to identify and manage early those affected to avoid the appearance of severe sequelae. Operational and bacilloscopic characterization of Hansen's disease patients positively contributes in the early diagnosis of reactions, because there is a higher chance of developing the reaction when the bacilloscopy is positive and the operational classification is multibacillary, supporting the importance of the results reported in this study. $]$ 


\section{REFERENCES}

1. Searo.who.int [Internet]. The eight report. WHO expert committee on leprosy, 2012 [cited 2017 apr 26]. Available from: http://www.searo.who.int/entity/global leprosy_programme/publications/8th_expert_comm_2012.pdf

2. Teixeira MA, Silveira VM, França $\overline{E R}$. Characteristics of leprosy reactions in paucibacillary and multibacillary individuals attended at two reference centers in Recife, Pernambuco. Rev Soc Bras Med Trop. 2010;43:287-92.

3. Lastória JC, Morgado de Abreu MAM. Leprosy: review of the epidemiological, clinical, and etiopathogenic aspects - Part 1. An Bras Dermatol. 2014;89:205-19.

4. Silva SF, Griep RH. Reação hansênica em pacientes portadores de hanseníase em centros de saúde da área de planejamento 3.2 do município do Rio de Janeiro. Hansen Int. 2007;32:155-62.

5. Nery JAC, Sales AM, Illarramendi X, Duppre NC, Jardim MR, Machado AM. Contribution to diagnosis and management of reactional states: a practical approach. An Bras Dermatol. 2006;81:367 $\neg 375$.
6. Reja AH, Biswas N, Biswas S, Dasgupta S, Chowdhury $\mathbb{H}$, Banerjee S, et al. FiteFaraco staining in combination with multiplex polymerase chain reaction: A new approach to leprosy diagnosis. Indian J Dermatol Venereol Leprol. 2013;79:693700.

7. Faria JL. Valor do método Faraco para coloração do bacilo de Hansen em cortes. Rev Bras Leprol. 1949;1:18-26.

8. Gallo MEN, Signorelli M, Albuquerque ECA, Nery JAC, Silva Filho M. Multibacillar leprosy: bacilloscopic index and viability of $\mathrm{M}$. leprae after 24 doses of multidrug therapy/World Health Organization (MDT/WHO). An Bras Dermatol. 2000;75:291-7.

9. Brito Mde F, Ximenes RA, Gallo ME, Bührer-Sékula S. Association between leprosy reactions after treatment and bacterial load evaluated using anti PGL-I serology and bacilloscopy. Rev Soc Bras Med Trop. 2008;41:67-72.

$\begin{array}{ll}\text { Marcel Alex Soares dos Santos } & \text { (iD) ORCID 0000-0002-5589-0931 } \\ \text { Larissa Mondadori Mercadante } & \text { (iD) ORCID 0000-0003-2648-2522 }\end{array}$

Elisangela Samartin Pegas

ORCID 0000-0002-9362-9814

Bogdana Victoria Kadunc
ORCID 0000-0001-9093-3872

How to cite this article: Santos MAS, Mercadante LM, Pegas ES, Kadunc BV. Relationship between bacilloscopy and operational classification of Hansen's disease in patients with reactions. An Bras Dermatol. 2018;93(3):454-6. 